AEs or whether adequate efficacy was achieved at lower doses, factors that may have influenced dose increases.

Funding. Teva Pharmaceutical Industries Ltd., Petach Tikva, Israel

\section{Single-Dose Pharmacokinetics of Amphetamine Extended-Release Oral Suspension (AMPH EROS) in 6-12-Year-Old Children with ADHD}

\author{
Antonio Pardo, $\mathrm{MD}^{1}$, Ann C. Childress, $\mathrm{MD}^{2}$, \\ Thomas R. King, MS, MPH ${ }^{1}$, Eman Rafla, MD $^{1}$ and \\ Judith C. Kando, PharmD, BCPP ${ }^{1}$
}

\section{Comparative Bioavailability of Amphetamine Extended-Release Oral Suspension and Extended- Release Mixed Amphetamine Salts}

${ }^{1}$ Tris Pharma, Inc., Monmouth Junction, NJ, USA, and ${ }^{2}$ Center for Psychiatry and Behavioral Medicine, Inc. Las Vegas, NV, USA

Presenting Author: Thomas R. King

Antonio Pardo, $\mathrm{MD}^{1}$, Mohammed Bouhajib, $\mathrm{MSc}^{2}$, Eman Rafla, $\mathrm{MD}^{1}$, Thomas R. King, MS, $\mathrm{MPH}^{1}$ and Judith C. Kando, PharmD, BCPP ${ }^{1}$

${ }^{1}$ Tris Pharma, Inc., Monmouth Junction, NJ, USA, and ${ }^{2}$ Pharma Medica Research Inc., Mississauga, Ontario, CA, USA

Presenting Author: Thomas R. King

\section{Abstract}

Purpose. This open-label, single-dose, randomized, two-period, two-treatment, two-sequence, crossover study evaluated the comparative bioavailability between amphetamine extended-release oral suspension (treatment A: AMPH EROS, Dyanavel XR 2.5 $\mathrm{mg} / \mathrm{mL}, 18.8 \mathrm{mg}$ amphetamine base per $7.5 \mathrm{~mL}$ ) and extendedrelease mixed amphetamine salts (treatment B: ER MAS, Adderall XR $30 \mathrm{mg}$ capsules, equivalent to $18.8 \mathrm{mg}$ amphetamine base per capsule) after a single dose in healthy adult subjects, under fasted conditions.

Methods. The crossover design allowed for intra-subject PK comparisons. Relative comparable bioavailability was determined by a statistical comparison of the AUC and Cmax parameters for both $\mathrm{d}$ - and l-amphetamine, where the geometric mean ratios for AUC and Cmax were within the $90 \%$ confidence limits $(80.0 \%-$ $125.0 \%)$ to determine comparable bioavailability between test products. Subjects in sequence 1 received treatment A followed by $B$; subjects in sequence 2 received treatment $B$ followed by treatment A. PK samples were obtained at 0 (pre-dose) through 60 hours post-dose. The safety assessment was based on reported frequency and severity of adverse events.

Results. Thirty (30) subjects were enrolled and 28 completed. The mean age of subjects was 35 years, with a mean BMI of 25.9 $\mathrm{kg} / \mathrm{m} 2$. Most subjects were Male (63.3\%) and Black (56.7\%). The geometric mean ratios for $\mathrm{Cmax}$ and all AUC measurements were within the $80-125 \%$ bound indicating comparable bioavailability between both test products. Both test products were generally well-tolerated with no serious AEs reported.

Conclusions. The bioavailability of a single $7.5 \mathrm{~mL}$ dose of AMPH EROS $2.5 \mathrm{mg} / \mathrm{mL}$ was comparable to a single $30 \mathrm{mg}$ capsule dose of ER MAS. AMPH EROS (both d- and l-amphetamine) showed equivalent peak and overall exposure to ER MAS under fasted conditions.

Funding. Tris Pharma, Inc.

\begin{abstract}
Methods. This Phase 1, open-label, single-dose, one-period, onetreatment PK study enrolled 12 children 6-12 y with ADHD. PK parameters for $\mathrm{d}$ - and l-amphetamine in plasma (Cmax, tmax, AUC0-8, and t1/2) were calculated and expressed as means, geometric means, and standard deviations. The primary endpoint was all objective PK measurements at 28 hours post-dose. PK was evaluated for 2 cohorts ( 6 pts ages 6-9 y and 6 pts aged 10-12 y). Safety was monitored continuously and assessed based on occurrence of adverse events.

Results. A single dose of $10 \mathrm{mg}(4 \mathrm{ml})$ AMPH EROS $(2.5 \mathrm{mg} / \mathrm{ml})$ administered under fasted conditions resulted in a rapid rise in mean plasma concentration in d-amphetamine, reaching maximum concentrations within 5 hours. The overall study population mean (SD) plasma AUC0-8 (d-amphetamine) was 1061.2 (309) $\mathrm{h}^{\star} \mathrm{ng} / \mathrm{mL}$, and for l-amphetamine was $380.5(112) \mathrm{h}^{*} \mathrm{ng} / \mathrm{mL}$. The mean maximum concentration (Cmax) for the overall study population was $54.91 \mathrm{ng} / \mathrm{mL}$ and 17.1 (5.2) ng/mL for d- and l-amphetamine, respectively. The overall study population median time to maximum concentrations (Tmax) for d-amphetamine were reached at 3.4 hours, and for l-amphetamine at 4.1 hours. The elimination half-life $(\mathrm{t} 1 / 2)$ for the entire study cohort was 10.6 (2.0) hours for d-amphetamine, and 12.5 (3.2) hours for l-amphetamine. Directionally, a higher mean Cmax, AUC0-8, AUCt, and median Tmax were observed in the younger (6 to 9-year-old) age group, and this result was consistent with both the $d$ - and l-amphetamine enantiomers. The mean elimination $t 1 / 2$ for both $\mathrm{d}$ - and l-amphetamine was higher in the older cohort (1012 years) than in the 6 to 12 -year-olds. Study drug was welltolerated by the subjects in this study. Two TEAEs were reported in one subject TEAEs (diarrhea and rash on legs) occurred approximately 12 hours postdose.

Conclusions. This study confirmed that the PK profile of AMPH EROS in 6 to 12 -year-olds provided a consistent, predictable extended-release profile in a highly titratable liquid formulation, and this finding was relatively consistent and directionally predictable between the age groups assessed, with higher maximum concentrations and AUCs and shorter elimination half-lives noted in the younger population, with no anomalous parameters demonstrated, and no untoward or unexpected safety issues noted.

Funding. Tris Pharma, Inc.
\end{abstract}

